\title{
PREVENTING TOMORROW'S SUDDEN CARDIAC DEATH IN EPILEPSY TODAY: WHAT SHOULD PHYSICIANS KNOW ABOUT THIS?
}

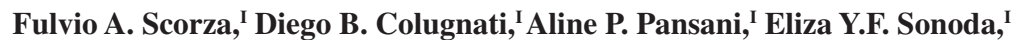 \\ Ricardo M. Arida, II Esper A. CavalheiroI
}

doi: $10.1590 / \mathrm{S1807-59322008000300017}$

Scorza FA, Colugnati DB, Pansani AP, Sonoda EYF, Arida RM, Cavalheiro EA. Preventing tomorrow's sudden cardiac death in epilepsy today: what should physicians know about this? Clinics. 2008;63:389-94.

Approximately $1 \%$ of the population has epilepsy, the most common neurological disorder. Moreover, people with epilepsy are more likely to die prematurely than those without epilepsy, and the most common epilepsy-related category of death is sudden unexpected death in epilepsy (SUDEP). Information concerning risk factors for SUDEP is conflicting, but potential risk factors include: age, early onset of epilepsy, duration of epilepsy, uncontrolled seizures, seizure frequency, number of antiepileptic drugs and winter temperatures. Additionally, the cause of SUDEP is still unknown; however, the most commonly suggested mechanisms are cardiac abnormalities during and between seizures. This review discusses the epidemiology, risk factors, etiology, and preventative measures in the management of SUDEP.

KEYWORDS: Epilepsy. Heart. Sudden cardiac death.

\section{EPILEPSY: GENERAL ASPECTS}

Epilepsy is the most common serious neurological condition and approximately 50 million people worldwide have it. ${ }^{1}$ In the US, about 100,000 new cases of epilepsy are diagnosed. ${ }^{2,3}$ In the UK, between 1 in 140 and 1 in 200 people (at least 300,000 people) are currently being treated for epilepsy. ${ }^{4}$ Epidemiological studies suggest that between 70 and $80 \%$ of people developing epilepsy will go into remission, while the remaining patients continue to have seizures and are refractory to treatment with the currently available therapies. ${ }^{5,6}$ The most common risk factors for epilepsy are cerebrovascular disease, brain tumours, alcohol, traumatic head injuries, malformations of cortical development, genetic inheritance, and infections of the

\footnotetext{
${ }^{\text {I }}$ Laboratório de Neurologia Experimental, Universidade Federal de São Paulo/Escola Paulista de Medicina (UNIFESP/EPM) - São Paulo/SP, Brasil. II Departamento de Fisiologia. Universidade Federal de São Paulo/Escola Paulista de Medicina (UNIFESP/EPM), São Paulo, Brasil. scorza.nexp@epm.br

Received for publication on December 19, 2007

Accepted for publication on January 16, 2008
}

central nervous system. In resource-poor countries, endemic infections, such as malaria and neurocysticercosis, seem to be major risk factors. ${ }^{8}$

Epilepsies are characterized by spontaneous recurrent seizures, caused by focal or generalized paroxysmal changes in neurological functions triggered by abnormal electrical activity in the cortex. ${ }^{9}$ Because it involves hyperexcitable neurons, a basic assumption links the pathogenesis of epilepsy and the generation of synchronized neuronal activity with an imbalance between inhibitory [g-aminobutyric acid (GABA)-mediated] and excitatory (glutamate-mediated) neurotransmission, in favor of the latter. ${ }^{10}$ Seizures and epilepsy are usually divided into two groups: partial and generalized. Partial or focal seizures have clinical or EEG evidence of local onset and may spread to other parts of the brain during a seizure, while generalized seizures begin simultaneously in both cerebral hemispheres. ${ }^{8}$ Temporal lobe epilepsy (TLE) is the most common form of partial epilepsy, probably affecting at least $20 \%$ of all patients with epilepsy. ${ }^{11}$ It is the most common form of drug-refractory epilepsy. ${ }^{12}$ Atrophy of mesial temporal structures is wellknown to be associated with TLE and hippocampal sclerosis, 
which is the most frequent histological abnormality in this form of epilepsy. ${ }^{13}$

\section{SUDDEN UNEXPECTED DEATH IN EPILEPSY}

Epilepsy is associated with a two- to three-fold increase in mortality compared to the general population, and sudden unexpected death in epilepsy (SUDEP) is the most important direct epilepsy-related cause of death. ${ }^{8}$ SUDEP is defined as non-traumatic and non-drowning death in patients with epilepsy that is sudden, unexpected, witnessed or unwitnessed, and with or without evidence of a seizure. Also in SUDEP, post mortem examination does not reveal a toxicological or anatomical cause of death (excluding documented status epilepticus). ${ }^{14}$ Comparisons of incidence estimates for SUDEP are difficult, since different definitions of SUDEP have been used, not all patients have a postmortem examination, and case ascertainment methods and source populations have varied..$^{15}$ The incidence of SUDEP has been estimated to be $3.5 / 1000$ person-years in a lamotrigine clinical trial, ${ }^{16} 0.5-1.4 / 1000$ person-years in people with treated epilepsy, ${ }^{17} 5.9 / 1000$ person-years in outpatients with epilepsy at a tertiary referral center, ${ }^{18}$ and $0.35 / 1000$ person-years in a population-based study. ${ }^{19}$ The National General Practice Study of Epilepsy (NGPSE), a community-based study in the United Kingdom, saw the first case of SUDEP after 11,000 person-years of follow-up, ${ }^{20}$ and the results of the Medical Research Council Antiepileptic Drug Withdrawal Study showed that SUDEP is a rare event among patients with epilepsy in remission..$^{21}$ Information concerning risk factors for SUDEP is conflicting, but potential risk factors include: early adulthood, ${ }^{16}$ early onset of epilepsy, ${ }^{22}$ long duration of epilepsy, ${ }^{23}$ uncontrolled seizures (mainly in those with TLE), ${ }^{23,24}$ high seizure frequency, ${ }^{23-25}$ certain seizure types, ${ }^{23,26}$ higher numbers of $\mathrm{AED}^{22,23,27}$ and winter temperatures. ${ }^{28}$ Additionally, potential pathomechanisms for SUDEP are unknown, but it is very probable that cardiac arrhythmias during and between seizures, electrolyte disturbances, arrhythmogenic drugs or transmission of epileptic activity to the heart via the autonomic nervous system potentially play a role. ${ }^{29}$

\section{CARDIAC ABNORMALITIES AND SUDEP}

By definition, the cause of death in SUDEP is currently unknown. A number of postmortem, ictal and interictal cardiac abnormalities do, however, suggest the possibility of seizure-induced cardiogenic SUDEP..$^{29,30}$

Postmortem examinations in people dying of SUDEP have found hearts that are dilated and heavier than expected ${ }^{16,29,31,32}$ and pulmonary edema in approximately
$50-86 \%$ of cases. ${ }^{16,26,29,32,33}$ Furthermore, others have described pathological changes in the hearts of those dying with SUDEP, including fibrosis of the walls of small coronary arteries, atrophy of cardiomyocytes, myofibrillar degeneration, edema of the conductive tissue and morphological abnormalities of the cardiac conduction system. ${ }^{26,29,31,34,35}$ These abnormalities may be the consequence of repeated hypoxemia and/or may be associated with the increase of catecholamines during an ictal sympathetic storm. ${ }^{29,31,34}$

Several studies have assessed the frequency and character of ictal cardiac rhythm during seizures, ${ }^{29,36,37}$ and the most compelling evidence derives from the presence of ictal arrhythmias. ${ }^{30}$ When ictal cardiorespiratory variables were recorded in people with epilepsy, an increase in heart rate in $91 \%$ of 41 seizures and a transient bradycardia in five seizures (four patients) were found. ${ }^{38}$ Another study evaluated the eletrocardiographic (ECG) changes during 51 seizures in 43 patients with refractory epilepsy. ${ }^{39}$ This showed that $70 \%$ of patients had either ECG abnormalities (16\%), tachycardias (30\%), or both (23\%) during the ictal and/or post-ictal period. These changes may all be relevant to the pathophysiology of SUDEP.

Results of interictal cardiac investigations have also been described. In one study, resting ECGs in 75 patients with epilepsy were compared with normal ECGs recorded in age-matched patients without cardiac or neurological disorders; ventricular rate, PR interval, QRS duration, and QT interval (corrected for heart rate) were compared. ${ }^{40}$ Those with epilepsy had higher heart rates and longer QT durations than the age-matched controls. Heart rate and QT duration were, however, not outside the normal range. Others investigated whether patients with drug refractory epilepsy have cardiovascular abnormalities that might be related to sudden death. ${ }^{41}$ Twenty-three subjects underwent comprehensive cardiovascular evaluations (ECG, Holtermonitoring, echocardiography, ergometric exercise test and myocardial scintigraphy; if abnormalities were found, coronary angiography was also performed) before and during video-EEG monitoring. ST-segment depression was found in $40 \%$, and this was associated with a higher maximum heart rate during seizures, suggesting that cardiac ischemia may occur in these patients. Although interictal changes in heart rate variability have been described in patients with epilepsy, their contribution to SUDEP remains to be determined.

\section{PREVENTATIVE MEASURES FOR SUDEP BE- YOND THERAPIES}

Preventative measures other than medical and surgical therapies could be useful in the prevention of SUDEP. 
Although the availability of pharmacological treatment of epilepsies has expanded, antiepileptic drugs are still limited in clinical efficacy. Genetic, environmental and social factors, among others, can contribute to the inefficacy of therapeutic outcome in people with epilepsy. Among these factors, nutritional aspects such as omega-3 fatty acid deficiency may play an interesting role. Substantial evidence from epidemiological and case-control studies indicates that omega- 3 reduces the risk of cardiovascular mortality, particularly sudden cardiac death. ${ }^{42}$ Following this reasoning, as omega-3 fatty acids per se have been shown to reduce cardiac arrhythmias and sudden cardiac deaths, it was hypothesised that omega-3 fatty acid supplementation in patients with refractory seizures may reduce seizures and seizure-associated cardiac arrhythmias, and hence, also SUDEP. ${ }^{4}$ Concerning the cardioprotective effects of omega-3, it has long been believed that a daily intake of 3000 to $4000 \mathrm{mg}$ of fish oil supplements or 2 to 3 servings of fatty fish per week are safe and effective in adults in general, including those with neurological diseases. ${ }^{43}$ It is very important to emphasise, however, that nutritional therapy, including omega-3 supplementation, is not a substitute for anticonvulsant medications.

Exposure to low temperatures is considered one of the main risk factors for cardiovascular abnormalities and hence, sudden death. ${ }^{44}$ There are several findings that may explain the increase in cardiac events in cold temperatures: 1) 53\% more cases of acute myocardial infarction are reported during the winter compared with the summer. ${ }^{45}$ Most reports, but not all, have demonstrated a significant winter increase in cardiovascular abnormalities and cardiac death, especially in the northern hemisphere where there are extreme winter temperatures. ${ }^{46,47}$ An increase in sudden cardiac death rate has, however, also been reported in the winter in regions where the winters are mild. ${ }^{48,49}$ 2) During the winter, increases in haemoconcentration (erythrocyte count, plasma cholesterol, and plasma fibrinogen levels) have been reported, which could contribute to arterial thrombosis. ${ }^{50} \mathrm{In}$ this way, rapid coronary deaths could result from rupture of atheromatous plaques during hemodynamic stress related to hypertension and cold-induced coronary spasm..$^{51,52} 3$ ) Cold weather can induce a higher systemic vascular resistance with an increase in blood pressure, thus increasing oxygen demand..$^{53}$ During a four-year period, the influence of climate on blood pressure in 53 patients with end-stage renal disease treated with haemodialysis was investigated. The authors showed that the mean systolic and diastolic blood pressures were highest during the winter (systolic 153 [SE 3] and diastolic 82 [SE 2] $\mathrm{mm} \mathrm{Hg}$ ) and lowest during the summer (systolic 141 [SE 3] and diastolic 75 [SE 2] mm Hg). 4) The winter temperatures may be associated with flu season, and an increase in upper respiratory tract infections could place stress on the heart..$^{54}$ One review noted that the incidence of acute myocardial infarction and atherosclerotic stroke and the incidence of upper respiratory infections (38\% of which are due to influenza) both peak in the winter months. It was suggested that, as studies have shown that influenza vaccination is associated with a $50 \%$ reduction in incidence of cardiovascular abnormalities and sudden cardiac death, much of this pathology could be prevented by yearly influenza vaccination. ${ }^{55}$

Taking these data into consideration, we believe that cold weather could be considered a new potential risk factor for sudden cardiac death in patients with epilepsy. ${ }^{28}$ Moreover, there is an urgent need for several studies (large-scale, prospective, community-based and international) of sudden cardiac death in epilepsy to explore the risk factors and help plan preventative strategies. In the meantime, the use of some medical or non-medical therapies may help to prevent sudden cardiac death in epilepsy. Along those lines, Kloner $(2004)^{54}$ described some very interesting common-sense and prudent tactics that physicians should consider during the winter time (termed "Merry Christmas Coronary" and "Happy New Year Heart Attack"), especially for patients with established cardiac disease or for those with known risk factors for cardiac disease: 1) instruct patients to avoid delay in seeking medical attention; 2) examine patients if possible, rather than relying upon healthcare providers not familiar with the patients; 3 ) ensure that coronary care units and emergency departments are adequately staffed; 4) instruct patients to avoid the known triggers for acute myocardial infarction, such as excess physical exertion (especially shovelling show), overeating, lack of sleep, emotional stress, illegal drugs and anger; 5) modify and treat known cardiovascular risk factors; 6) consider aspirin or ß-blockers, or both, if appropriate; 7) instruct patients to avoid exposure to severely cold temperatures; 8) consider flu shots when appropriate.

Others have suggested, since winter mortality in the UK is now not primarily caused by failure to heat homes, the reduction of outdoor cold stress, such as by heating waiting areas for public transport, should be considered. ${ }^{57}$

Finally, several suggestions have been made concerning the mechanisms behind SUDEP, most involving speculation about the possible role of autonomic effects such as cardiorespiratory disturbances. It has been believed that cardiovascular diseases are often associated with overactivity of the sympathetic nervous system $^{58}$ and that increases in physical activity produce beneficial effects on the cardiovascular system in both normal and diseased individuals via alteration of neural control of the circulation. ${ }^{59,60}$ These effects include reductions in blood 
pressure and sympathetic outflow in humans ${ }^{61}$ as well as in animal models of exercise training. ${ }^{62,63}$ Since morbidity and mortality in cardiovascular disease are often associated with elevation of sympathetic nervous system activity, ${ }^{64}$ the beneficial effects of physical activity are probably related, in part, to reduction of sympathetic activity. A recent study by our group evaluated the heart rate, in vivo (ECG) and isolated ex vivo preparation (Langendorf preparation) of rats with epilepsy. ${ }^{65}$ The results showed differences in the mean heart rate in vivo, but surprisingly, no differences in heart rate could be observed in the isolated ex vivo situation, suggesting a central nervous system modulation of the heart that could explain SUDEP. ${ }^{65}$

Taking these findings together, it is very reasonable to think that regular physical activity is able to attenuate sympathetic nervous system activity, cardiac abnormalities and hence SUDEP. Furthermore, it is clear that premature mortality is increased in patients with epilepsy, particularly in those with more severe seizures,${ }^{15}$ and it is generally acknowledged that the incidence of cardiac abnormalities between seizures is the very probable cause of SUDEP. ${ }^{15,29}$ Since physical activity has been considered to have anticonvulsant effects, ${ }^{66-68}$ it is possible to propose that regular physical activity may attenuate the frequency of seizures and cardiac abnormalities that could culminate in SUDEP.

In conclusion, as reported by others, ${ }^{69}$ clarification of risk factors and establishment of the mechanisms of SUDEP are important for establishing preventative measures for SUDEP and for striving for the best control of seizures. However, it is conceivable that encouraging patients with epilepsy worldwide to receive non-pharmacological treatments will lead to substantial public-health benefits.

\section{REFERENCES}

1. Sander JW. The epidemiology of epilepsy revisited. Curr Opin Neurol. 2003;16:165-70.

2. Begley CE, Annegers JF, Lairson LB, Reynolds TF. Epilepsy incidence, prognosis, and use of medical care in Houston, Texas, and Rochester, Minnesota. Epilepsia. 1998;39 (Suppl 6):222.

3. Annegers JF. Epidemiology of epilepsy. In: Wyllie E, editor. The treatment of epilepsy: principles and practice. 2nd ed. Baltimore: Williams \& Wilkins; 1997. p. 165-72.

4. Yuen AW, Sander JW. Is omega-3 fatty acid deficiency a factor contributing to refractory seizures and SUDEP? A hypothesis. Seizure. 2004;13:104-7.

5. Kwan P, Sander JW. The natural history of epilepsy: an epidemiological view. J Neurol Neurosurg Psychiatry. 2004;75:1376-81.

6. Sander JW. Some aspects of prognosis in the epilepsies: a review. Epilepsia. 1993;34:1007-16.

7. Halatchev VN. Epidemiology of epilepsy--recent achievements and future. Folia Medica (Plovdiv). 2000;42:17-22.

8. Duncan JS, Sander JW, Sisodiya SM, Walker MC. Adult epilepsy. Lancet. 2006;367:1087-100.

9. Dichter MA. Emerging insights into mechanisms of epilepsy: implications for new antiepileptic drug development. Epilepsia. 1994;35 (Suppl 4):S51-S57.

10. Dalby NO, Mody I. The process of epileptogenesis: a pathophysiological approach. Curr Opin Neurol. 2001;14:187-92.

11. Babb TL. Synaptic reorganizations in human and rat hippocampal epilepsy. Adv Neurol. 1999;79:763-79.
12. Engel J Jr. Clinical neurophysiology, neuroimaging, and the surgical treatment of epilepsy. Curr Opin Neurol Neurosurg. 1993;6:240-9.

13. Cendes F.Progressive hippocampal and extrahippocampal atrophy in drug resistant epilepsy. Curr Opin Neurol. 2005;18:173-7.

14. Nashef L. Sudden unexpected death in epilepsy: terminology and definitions. Epilepsia. 1997;38:S6-S8.

15. Tomson T, Walczak T, Sillanpaa M, Sander JW. Sudden unexpected death in epilepsy: a review of incidence and risk factors. Epilepsia. 2005;46 (Suppl 11):54-61.

16. Leestma JE, Annegers JF, Brodie MJ, Brown S, Schraeder P, Siscovick D, Wannamaker BB, Tennis PS, Cierpial MA, Earl NL. Sudden unexplained death in epilepsy: observations from a large clinical development program. Epilepsia. 1997;38:47-55.

17. Tennis P, Cole TB, Annegers JF, Leestma JE, McNutt M, Rajput A. Cohort study of incidence of sudden unexplained death in persons with seizure disorder treated with antiepileptic drugs in Saskatchewan. Canada. Epilepsia. 1995;36:29-36.

18. Nashef L, Fish DR, Sander JW, Shorvon SD. Incidence of sudden unexpected death in an adult outpatient cohort with epilepsy at a tertiary referral centre. J Neurol Neurosurg Psychiatr. 1995;58:462-4.

19. Ficker DM, So EL, Shen WK, Annegers JF, O'Brien PC, Cascino GD, Belau PG. Population-based study of the incidence of sudden unexplained death in epilepsy. Neurology. 1998;515:1270-4.

20. Lhatoo SD, Sander JW. The epidemiology of epilepsy and learning disability. Epilepsia. 2001. 42 suppl 1:6-9.

21. Medical Research Council Antiepileptic Drug Withdrawal Study Group. Randomised study of antiepileptic drug withdrawal in patients in remission. Lancet. 1991;337:1175-80. 
22. Nilsson L, Farahmand BY, Persson PG, Thiblin I, Tomson T. Risk factors for sudden unexpected death in epilepsy: a case-control study. Lancet. 1999;353:888-93.

23. Walczak TS, Leppik IE, D’Amelio M, Rarick J, So E, Ahman P, Ruggles $\mathrm{K}$, Cascino GD, Annegers JF, Hauser WA. Incidence and risk factors in sudden unexpected death in epilepsy: a prospective cohort study. Neurology. 2001;56:519-25.

24. Sperling MR, Feldman H, Kinman J, Liporace JD, O’Connor MJ. Seizure control and mortality in epilepsy. Ann Neurol. 1999;46:45-50.

25. Langan Y, Nashef L, Sander JW. Case-control study of SUDEP. Neurology. 2005;64:1131-3.

26. Kloster R, Engelskjon T. Sudden unexpected death in epilepsy (SUDEP): a clinical perspective and a search for risk factors. J Neurol Neurosurg Psychiatr. 1999;67:439-44.

27. Nilsson L, Bergman U, Diwan V, Farahmand BY, Persson PG, Tomson T. Antiepileptic drug therapy and its management in sudden unexpected death in epilepsy: a case-control study. Epilepsia. 2001;42:667-73.

28. Scorza FA, de Albuquerque M, Arida RM, Cavalheiro EA,. Sudden unexpected death in epilepsy: Are winter temperatures a new potential risk factor? Epilepsy Behav. 2007;10:509-10.

29. Stollberger C, Finsterer J. Cardiorespiratory findings in sudden unexplained/unexpected death in epilepsy (SUDEP). Epilepsy Res. 2004;59:51-60

30. Ryvlin P, Montavont A, Kahane P. Sudden unexpected death in epilepsy: from mechanisms to prevention. Curr Opin Neurol. 2006;19:194-99.

31. Falconer B, Rajs J. Post-mortem findings of cardiac lesions in epileptics: a preliminary report. Forensic Sci. 1976;8:63-71.

32. Leestma JE, Walczak T, Hughes JR, Kalelkar MB, Teas SS. A prospective study on sudden unexpected death in epilepsy. Ann Neurol. 1989;26:195-203.

33. Thom M, Seetah S, Sisodiya S, Koepp M, Scaravilli F. Sudden and unexpected death in epilepsy (SUDEP): evidence of acute neuronal injury using HSP-70 and c-Jun immunohistochemistry. Neuropathol Appl Neurobiol. 2003;29:132-43.

34. Natelson BH, Suarez RV, Terrence CF, Turizo R. Patients with epilepsy who die suddenly have cardiac disease. Arch Neurol. 1998;55:857-60.

35. Opeskin K, Thomas A, Berkovic SF. Does cardiac conduction pathology contribute to sudden unexpected death in epilepsy? Epilepsy Res. 2000;40:17-24.

36. Keilson MJ, Hauser WA, Magrill JP, Goldman M. ECG abnormalities in patients with epilepsy. Neurology. 1987;37:1624-6.

37. Opherk C, Coromilas J, Hirsch LJ. Heart rate and EKG changes in 102 seizures: analysis of influencing factors. Epilepsy Res. 2002;52:117-27.

38. Nashef L, Walker F, Allen P, Sander JW, Shorvon SD, Fish DR. Apnoea and bradycardia during epileptic seizures: relation to sudden death in epilepsy. J Neurol Neurosurg Psychiatry. 1996;60:297-300.

39. Nei M, Ho RT, Sperling MR. EKG abnormalities during partial seizures in refractory epilepsy. Epilepsia. 2000;41:542-8.

40. Drake ME, Reider CR, Kay A. Electrocardiography in epilepsy patients without cardiac symptoms. Seizure. 1993;2:63-5.
41. Tigaran S, Molgaard H, McClelland R, Dam M, Jaffe AS. Evidence of cardiac ischemia during seizures in drug refractory epilepsy patients. Neurology. 2003;60:492-5.

42. Calder PC. n-3 fatty acids and cardiovascular disease: evidence explained and mechanisms explored, Clin Sci. 2004;107:1-11.

43. Mazza M, Pomponi M, Janiri L, Bria P, Mazza S. Omega-3 fatty acids and antioxidants in neurological and psychiatric diseases: an overview, Prog Neuropsychopharmacol Biol Psychiatry. 2007;31:12-26.

44. Arntz HR, Willich SN, Schreiber C, Brãggemann T, Stern R, Schultheiss HP. Diurnal, weekly and seasonal variation of sudden death. Population based analysis of 24,061 consecutive cases. Eur Heart J. 2000;21:315-20.

45. Spencer FA, Goldberg RJ, Becker RC, Gore JM. Seasonal distribution of acute myocardial infarction in the second National Registry of Myocardial Infarction. J Am Coll Cardiol. 1998;31:1226-33.

46. Beyerbach M, Kovacs RJ, Dmitrienko AA, Rebhun DM, Zipes DP. Heart rate-corrected QT interval in men increases during winter months. Heart Rhythm. 2007;4:277-81.

47. Beard CM, Fuster V, Elveback LR. Daily and seasonal variation in sudden cardiac death, Rochester, Minnesota, 1950-1975. Mayo Clin Proc. 1982;57:704-6.

48. Kloner RA, Poole WK, Perritt RL. When throughout the year is coronary death most likely to occur? Circulation. 1999;100:1630-4.

49. Douglas AS, Al-Sayer H, Rawles JM, Allan TM. Seasonality of disease in Kuwait. Lancet. 1991;337:1393-7.

50. Neild PJ, Syndercombe-Court D, Keatinge WR, Donaldson GC, Mattock M, Caunce M . Cold-induced increases in erythrocyte count, plasma cholesterol and plasma fibrinogen of elderly people without a comparable rise in protein C or factor X. Clin Sci. 1994;86:43-8.

51. Farb A, Tang AL, Burke AP, Sessums L, Liang Y, Virmani R. Sudden coronary death: requency of active coronary lesions, inactive coronary lesions, and myocardial infarction. Circulation. 1995;92:1701-9.

52. Collins KJ, Easton JC, Belfield-Smith H, Exton-Smith AN, Pluck RA. Effects of age on body temperature and blood pressure in cold environments, Clin Sci. 1985;69:465-70.

53. Argiles A, Mourad G, Mion C. Seasonal changes in blood pressure in patients with end-stage renal disease reated with hemodialysis. N Engl J Med. 1998;339:1364-70.

54. Fleming DM, Cross KW, Pannell RS. Influenza and its relationship to circulatory disorders. Epidemiol Infect. 2005;133:255-62.

55. Meyers DG. Myocardial infarction, stroke, and sudden cardiac death may be prevented by influenza vaccination. Curr Atheroscler Rep. $2003 \cdot 5: 146-9$

56. Kloner RA. The "Merry Christmas Coronary" and "Happy New Year Heart Attack" phenomenon. Circulation. 2004;110:3744-5.

57. Keatinge WR, Donaldson GC. Winter mortality in elderly people in Britain: action on outdoor cold stress is needed to reduce winter mortality. BMJ. 2004;329:976.

58. Schlaich MP, Lambert E, Kaye DM, Krozowski Z, Campbell DJ, Lambert G, Hastings J, Aggarwal A, Esler MD. Sympathetic augmentation in hypertension: role of nerve firing, norepinephrine reuptake, and Angiotensin neuromodulation. Hypertension. 2004;43:169-75. 
59. Billman GE. Aerobic exercise conditioning: a nonpharmacological antiarrhythmic intervention. J Appl Physiol. 2002;92:446-54.

60. Cornelissen VA, Fagard RH. Effects of endurance training on blood pressure, blood pressure-regulating mechanisms, and cardiovascular risk factors. Hypertension. 2005;46:667-75.

61. Pescatello LS, Franklin BA, Fagard R, Farquhar WB, Kelley GA, Ray CA. American College of Sports Medicine. American College of Sports Medicine position stand. Exercise and hypertension. Med Sci Sports Exerc. 2004;36:533-53.

62. De Angelis K, Wichi RB, Jesus WR, Moreira ED, Morris M, Krieger EM, Irigoyen MC. Exercise training changes autonomic cardiovascular balance in mice. J Appl Physiol. 2004;96:2174-8.

63. Krieger EM, Da Silva GJ, Negrao CE. Effects of exercise training on baroreflex control of the cardiovascular system. Ann N Y Acad Sci. 2001;940:338-47.

64. Zoccali C, Mallamaci F, Parlongo S, Cutrupi S, Benedetto FA, Tripepi G, Bonanno G, Rapisarda F, Fatuzzo P, Seminara G, Cataliotti A, Stancanelli B, Malatino LS. Plasma norepinephrine predicts survival and incident cardiovascular events in patients with end-stage renal disease. Circulation. 2002;105:1354-9.
65. Colugnati DB, Gomes PA, Arida RM, de Albuquerque M, Cysneiros RM, Cavalheiro EA, Scorza FA. Analysis of cardiac parameters in animals with epilepsy: possible cause of sudden death? Arq de Neuropsiq. 2005;63:1035-41.

66. Arida RM, Vieira AJ, Cavalheiro EA. Effect of physical exercise on kindling development. Epilepsy Res. 1998;30:127-32.

67. Arida RM, Scorza FA, Santos NF, Peres CA, Cavalheiro EA. Effect of physical exercise on seizure occurrence in a model of temporal lobe epilepsy in rats. Epilepsy Res. 1999;37:45-52.

68. Arida RM, Scorza CA, Scorza FA, Gomes da Silva S, da Graca Naffah- Mazzacoratti M, Cavalheiro EA. Effects of different types of physical exercise on the staining of parvalbumin-positive neurons in the hippocampal formation of rats with epilepsy. Prog Neuropsychopharmacol Biol Psychiatry. 2007;31:814-22.

69. Bell Gs, Sander JW. Sudden unexpected death in epilepsy. Risk factors, possible mechanisms and prevention: a reappraisal. Acta Neurol Taiwan. 2006;15:72-83. 